\title{
Prevalence of Klebsiella Pneumoniae Isolated from Pregnant Women with Urinary Tracts Infections
}

\section{Farouk S. Nas ${ }^{1}$, Ibrahim U. Imam ${ }^{2}$, Abdullahi Yahaya ${ }^{3}$, Bello A. Jido ${ }^{3}$, Muhammad Ali ${ }^{4 *}$}

${ }^{1}$ Department of Biological Sciences, Bayero University Kano, Nigeria.

${ }^{3}$ Department of Vector and Parasitology, Nigerian Institute for Trypanosomiasis and Onchocerciasis Research Kaduna, Nigeria.

${ }^{3}$ Department of Biological Sciences, Kano University of Science and Technology Wudil, Nigeria.

${ }^{4}$ Department of Microbiology, Federal University Gusau, Nigeria. alimuhd4real@gmail.com

*Corresponding Author: Muhammad Ali, Department of Microbiology, Federal University Gusau, Nigeria.

Abstract

Urinary tract infection (UTI) is very common medical complications of pregnancy due to anatomic and physiological changes that occur in pregnancy. The objective of the study is to determine the prevalence of Klebsiella pneumonia isolated from pregnant women with urinary tract infections attending Murtala Muhammad Specialist Hospital Kano, Nigeria. A total of 145 urine samples of pregnant women coming for ante-natal care at maternity ward of Murtala Muhammad Specialist Hospital Kano were collected for period of 6 month from March, 2017 to August, 2017. Each sample was streaked using a sterilized platinum wire loop onto the surface of freshly prepared MacConkey and Nutrient agar plates for isolation of K. pneumonia. Isolates were subjected to Gram staining, indole, citrate utilization, methyl-red, voges Proskauer and nitrate reduction test for identification. The results showed that out of the total of 145 subjects examined, 23 subjects were diagnosed with urinary tract infection which accounted for $15.8 \%$ of the pregnant women. The findings of the study showed that K. pneumoniae is Gram negative rod bacterium, non-motile, positive for nitrate reduction, $V P$ and citrate utilization test, negative for indole and MR test and lactose fermenter. The result showed that 12 out of 23 urine samples were positive for K. pneumoniae which accounted for 52.1\%. it is concluded that K. pneumoniae is one of the etiological agent of urinary tract infection.

Keywords: Urinary tract infection, prevalence, pregnant women, K. pneumoniae

\section{INTRODUCTION}

Urinary tract infections (UTIs) are one of the most common infectious diseases [1]. They may be symptomatic or asymptomatic, and either type of infection can result in serious and complicated if not appropriately treated [2]. Although different causative agents can be responsible for UTIs, bacteria are the major cause being responsible for more than $95 \%$ of UTI cases [3]. The infection is mainly caused by gram-negative organisms that include $E$. coli $60-70 \%$, Klebsiella 10\%, Proteus 5-10\%, and Pseudomonas 2-5\% and gram-positive bacteria, group B Streptococcus and Staphylococcus species [4]. The gram-positive pathogens are Streptococcus species and Staphylococcus species [5,6]. According to Ronaldo [7], the common etiologic agents of UTI include Escherichia coli, Klebsiella sp, Staphylococcus aureus, Pseudomonas $s p$ and Streptococcus. These organisms are mainly from the external genitalia, vagina, the genital tract, rectum, and gastro-intestinal tract. It may involve the lower urinary tract or the bladder [8].

Klebsiella pneumoniae is a gram negative, non-motile, encapsulated, lactose fermenting, facultative anaerobe, catalase positive, oxidase negative belonging to the Enterobacteriaceae family [9]. It is the most common causative agent of nosocomial and community acquired 
infections. It is also responsible for pneumonia, mastitis, endometritis and urinary tract infection. Klebsiella sp are often resistant to many antibiotics, including cephalosporins and aminoglycosides [10]. These bacteria have become important pathogens in nosocomial infections [11], which have been well documented in United States [12] and India [13]. Epidemic and endemic nosocomial infections caused by Klebsiella species are leading causes of morbidity and mortality. Klebsiella pneumoniae can also cause a urinary tract infection in children and adults. In the United States, it is accounts for 3-7\% of all nosocomial bacterial infections, placing them among the eight most important infectious pathogens in hospitals and also important opportunistic pathogens [14]. Clinical isolates of $K$. pneumoniae are generally resistant to a wider range of antibiotics, and virtually always naturally resistance to ampicillin and amoxicillin. $\beta$-lactam antimicrobial agents are most common treatment option for such infections [15].

Excessive or in some cases inappropriate use of antibiotics in treating UTIs is responsible for the emergence and spread of multi-drug resistant (MDR) urinary bacteria [16]. UTIs caused by MDR Klebsiella pneumonia isolates are a major public health problem, since the therapeutic options significantly reduced and more challenging in clinical scenario. Moreover, MDR pathogens resulting in high morbidity and mortality as they reflect in increased hospital stay and treatment expenditure [16]. The development of drug-resistant pathogens in patients with serious infections such as UTIs has generally been ascribed to the widespread use of antimicrobial agents and the limited availability of infection prevention and control programs. As a result, it is increasingly common to encounter individuals infected with bacterial pathogens that are resistant to almost all currently available antibiotics [17]. The objective of the study is to determine the prevalence of Klebsiella pneumonia isolated from pregnant women with urinary tract infections attending Murtala Muhammad Specialist Hospital Kano, Nigeria.

\section{Materials ANd Methods}

\section{Ethical Consideration}

An approval (MOH/off/797/T.I/49) for the study was obtained from Research and Ethic committee
Kano State Ministry of Health through Health Service Management Board (HMB). The aim of the study was explained clearly to the clients and informed consent obtained before proceeding to the study.

\section{Study Area}

The study was conducted at maternity ward of Murtala Muhammad Specialist Hospital (MMSH), Kano. Kano state is located in the North-Western Nigeria with coordinates $11^{0} 30 \mathrm{~N} 8^{0} 30 \mathrm{E}$. It shares borders with Kaduna state to the south- west, Bauchi state to the South-East, Jigawa state to the East, Katsina state to the West and Niger republic to the North. It has a total area of $20,131 \mathrm{~km}^{2}(7,777 \mathrm{sqm})$ and population of $11,058,300$ [18].

\section{Determination of Sample Size}

The sample size for the study was determined from a standard epidemiology formula for minimum sample size calculation [19]. The sample size was given by the formula below;

$\mathrm{N}=\left(\mathrm{Z}_{1}-\mathrm{a}\right)^{2}(\mathrm{p})(1-\mathrm{p}) / \mathrm{d}^{2}$

$\mathrm{N}=$ minimum sample size

$\mathrm{Z}_{1--} \mathrm{a}=$ value of standard normal deviate which at $95 \%$ confidence interval has found to be 1.96 .

$\mathrm{P}=$ the best estimate of prevalence obtained from literature review (9.5\%) and

$\mathrm{d}=$ difference between the true population rate and sample that can be tolerated, this is the absolute precision (in percentage) on either side of the population.

$\mathrm{N}=(1.96)^{2}(0.095)(1-0.095) /(0.05)^{2}=132.05$ as the minimum number of sample for the study. Therefore, a total of 132 with $10 \%$ (13) of this subject will be added to the research for attrition, making a total of approximately 145 samples.

\section{Study Population}

A total of 145 urine samples of pregnant women coming for ante-natal care at maternity ward of Murtala Muhammad Specialist Hospital Kano were collected for period of 6 month from March, 2017 to August, 2017. The subjects were approached and requested for voluntary consent to participate in the study. The inclusive criteria involve pregnant women complaining of lower abdominal pain. 
Prevalence of Klebsiella Pneumoniae Isolated from Pregnant Women with Urinary Tracts Infections

Table 1. The age distribution of the study subjects

\begin{tabular}{|c|c|c|}
\hline Parameters & Frequency (n) & Percentage (\%) \\
\hline Age (years) & & 08.3 \\
\hline Less than 20 & 12 & 26.9 \\
\hline $21-25$ & 39 & 38.6 \\
\hline $26-30$ & 56 & 21.4 \\
\hline $31-35$ & 31 & 04.8 \\
\hline $36-40$ & 07 & $\mathbf{1 0 0}$ \\
\hline Total & $\mathbf{1 4 5}$ & \\
\hline
\end{tabular}

\section{Samples Collection}

Early morning mid-stream urine samples of about 10 $\mathrm{ml}$ were collected from pregnant women complaining of urinary tract infection using clean and sterilized plastic bottles with air-tight screw cap tops. Each urine sample bottle was labeled with a reference code, age, occupation, socio-economic status, and age of gestation. The samples were placed in a cold box for transportation to the laboratory, where it was stored until analyses were carried out. All samples were analyzed with the microbial culture method and conventional urine analysis.

Culturing, Isolation and Identification of Bacteria

Each of urine samples was streaked using a sterilized platinum wire loop onto the surface of MacConkey and Nutrient agar plates. The plates were incubated at $37^{\circ} \mathrm{C}$ for 24 hours to isolate the growing microorganisms. Representative of growing colonies were picked with a sterile wire loop and re-inoculated onto the surface of nutrient agar, pure cultures were made with repeated streaking. The resulting pure colonies obtained were used for biochemical tests aimed at identifying the bacteria isolates. Isolates were particularly subjected to Gram staining, indole, citrate utilization, motility, methyl-red and voges proskauer and test.

\section{Gram's Stain}

The smear was made from the isolate on a clean grease free slide and allowed to air dried and fix. The smear was flooded with crystal violet as a primary stain and was allowed to stain for 2 minutes and rinsed with water. A mordant (lugol's iodine) was then flooded and allowed to stay for 1 minute and rinsed with water. A smear was then flooded with secondary stain (neutral red) and was allowed to stain for 2 minutes and then rinsed in water and allowed to air dried [20].

\section{Citrate Utilization Test}

The surface of the Simmons citrate agar slant was streaked with a portion of a well isolated colony. The cap of the slant was left on loosely and was incubates at $35^{\circ} \mathrm{C}$ for $18-24$ hours [21].

\section{Indole Test}

Tryptophan broth was inoculated with an isolate of the test organism and incubated at $37^{\circ} \mathrm{C}$ for 24 hours. About $0.5 \mathrm{ml}$ of Kovack's reagents was added to the broth culture [20].

\section{Methyl Red Test}

MR-VP broth was inoculated with an isolate of the test organism using sterile inoculating loop and incubated at $37^{\circ} \mathrm{C}$ for 24 hours. About 5 drops of Methyl-red reagent was added to the broth culture [20].

\section{Voges Proskauer}

MR-VP broth was inoculated with an isolate of the test organism using sterile inoculating loop and incubated at $37^{\circ} \mathrm{C}$ for 24 hours. Six millilitres $(6 \mathrm{ml})$ of $5 \%$ alpha naphthol was added followed by $0.2 \mathrm{ml}$ of $\mathrm{KOH}$. The tube was shaken gently and remained undisturbed for 5 minutes [20].

\section{Nitrate Reduction Test}

Nitrate broth was inoculated with an isolate of the test organism using sterile inoculating loop and incubated at $37^{\circ} \mathrm{C}$ for 24 hours. A dropper full of sulfanilic acid and that of $\alpha$ naphthalamine were added to the broth [21].

\section{Motility Test}

A semi solid medium in a test tube was inoculated 
Prevalence of Klebsiella Pneumoniae Isolated from Pregnant Women with Urinary Tracts Infections

with an isolate of the test organism using straight sterile wire and making a single stab at the centre of the test tube. The test tube was incubated at $37^{\circ} \mathrm{C}$ and examined the stab line at various intervals to determine motility [20].

\section{Statistical Analysis}

Statistical analysis Package for Social Science (SPSS) version 10.0 was used for statistical analysis of the data generated. Chi square was used to compare between two or more variables. Statistical significance was considered at $p$-value $<0.05$ and confidence level of $95 \%$.

\section{RESULT}

\section{Prevalence of Urinary Tract Infections}

The prevalence of urinary tract infections among pregnant women coming for ante-natal at maternity ward of the Hospital is presented in the table below (Table 2). The results showed that out of the total of 145 subjects, 23 subjects were diagnosed with urinary tract infection which accounted for $15.8 \%$ of the pregnant women. Prevalence of UTI among pregnant women showed that higher incidence found among subjects of age category 26 - 30 years.

Table 2. The prevalence of urinary tract infections among pregnant women

\begin{tabular}{|c|c|c|c|c|}
\hline Age (years) & Frequency (n) & UTI + & UTI- & $\mathbf{X}^{\mathbf{2}}$ \\
\hline Less than 20 & 12 & 03 & 09 & $1.4045^{*}$ \\
\hline $21-25$ & 39 & 06 & 33 & \\
\hline $26-30$ & 56 & 07 & 49 & \\
\hline $31-35$ & 31 & 05 & 26 & \\
\hline $36-40$ & 07 & 02 & 05 & \\
\hline Total & $\mathbf{1 4 5}$ & $\mathbf{2 3}(\mathbf{1 5 . 8 \% )}$ & $\mathbf{1 2 2} \mathbf{( 8 4 . 2 \% )}$ & \\
\hline
\end{tabular}

Key: * The result is not significant at $p<0.05$

Cultural and Biochemical Characterization of K. pneumoniae

The cultural and biochemical characteristics of $K$. pneumoniae are presented in Table 3. The result shows that K. pneumoniae was found to be Gram negative rod with shiny mucoid/viscous colony appearance on Nutrient agar plate and pinkish/mucoid colony in MacConkey agar plate.

Table 3. Cultural and Biochemical characteristics of the recovered isolates

\begin{tabular}{|c|c|c|}
\hline S/N & Test & K. pneumoniae \\
\hline 1 & Gram staining & Gram negative \\
\hline 2 & Shape & Rod \\
\hline 3 & Cultural appearance & - \\
\hline 4 & MacConkey growth & - \\
\hline 5 & Indole test & + \\
\hline 6 & Methyl-red test & + \\
\hline 7 & Voges Proskauer test & - \\
\hline 8 & Citrate utilization test & + \\
\hline 9 & Motility test & + \\
\hline 11 & Nitrate reduction test & + Produce pinkish and mucoid colony \\
\hline 12 & Lactose fermentation & - \\
\hline
\end{tabular}

\section{Prevalence of $K_{\text {. pneumoniae }}$}

The prevalence of $K$. pneumoniae among the urine samples in relation to age category of the subjects is presented in Table 4. A total of 23 urine samples were examined for the presence of $K$. pneumoniae.
The result showed that 12 samples were positive for K. pneumoniae which accounted for 52.1\%. Higher incidence of the isolates was found among subjects with age category 26 - 30 years with prevalence of $17.4 \%$. Least prevalence was recoding among subjects with age category 36 - 40 with $4.3 \%$. 
Prevalence of Klebsiella Pneumoniae Isolated from Pregnant Women with Urinary Tracts Infections

Table 4. Prevalence of K. pneumoniae with respect to age of the subject

\begin{tabular}{|c|c|c|c|c|}
\hline Age (years) & Samples examine (n) & Klebsiella positive (n) & Prevalence (\%) & $\mathbf{X}^{\mathbf{2}}$ \\
\hline Less than 20 & 03 & 02 & 08.7 & $3.1776^{*}$ \\
\hline $21-25$ & 05 & 03 & 13.0 & \\
\hline $26-30$ & 10 & 04 & 17.4 & \\
\hline $31-35$ & 04 & 02 & 08.7 & \\
\hline $36-40$ & 01 & 01 & 04.3 & \\
\hline Total & $\mathbf{2 3}$ & $\mathbf{1 2}$ & $\mathbf{5 2 . 1}$ & \\
\hline
\end{tabular}

Key: *The $p$-value is 0.528557 . The result is statistically not significant at $p<0.05$

\section{DisCUSSION}

Urinary tract infection (UTI) is very common medical complications of pregnancy due to anatomic and physiological changes that occur in pregnancy. The physiological changes increase the vulnerability to the development of asymptomatic to pyelonephritis which may result in maternal morbidity and poor fetal outcome [24]. The present study was aimed to determine the prevalence of Klebsiella pneumonia isolated from pregnant women with urinary tract infections attending ante-natal at maternity ward of Murtala Muhammad Specialist Hospital Kano, Nigeria.

In the present study, a total of 145 cases were considered of which 23 cases accounted for 15.8\% were UTI positive while 122 cases (84.2\%) were UTI negative. The overall prevalence of urinary tract infection among pregnant women complaining of lower abdominal pains in this study was found to be $15.8 \%$. This result was in conformity with similar study conducted by Mikhail and Anyaegbunam [25] in Northern Tanzania who found the prevalence of UTI among pregnant women as $16.4 \%$. Another study conducted by Muhammad and Fareid [26] found 14.6\% as the percentage prevalence of pregnant women with Urinary tract infection. The result also correlates with that found in Khartoum, Sudan (14\%). On the other hand, the result of the present study is in contrast with that of Nabbugodi et al. [27] who found prevalence of UTI among pregnant women as $26.7 \%$. The differences in prevalence may be explained due to differences in socio-economic status, environmental condition, social habit, personal hygiene and educational level. Prevalence of UTI among pregnant women showed that higher incidence found among subjects of age category $26-30$ years. However, the result is not significant. This finding was in conformity with that of Nwachukwu et al. [28] who study the prevalence of urinary tract infections in pregnant women in Onitsha, Nigeria who found similar result. Higher incidence among pregnant women in this category may be as result of higher sexual activity and women at this stage more sexually active which in turn increase the risk of UTI.

The findings of the study showed that $K$. pneumoniae is Gram negative rod bacterium, non-motile, positive for nitrate reduction, VP and citrate utilization test, negative for indole and MR test and lactose fermenter. This result correlates with the finding of Hind et al. [9]. Klebsiella pneumoniae can also cause a urinary tract infection in children and adults, and accounted for 3$7 \%$ of all nosocomial bacterial infections, placing them among the eight most important infectious pathogens in hospitals and also important opportunistic pathogens [14].

For the prevalence of $K$. pneumoniae in the study, a total of 23 urine samples were examined for the presence of isolates. The result showed that 12 samples were positive for $K$. pneumoniae which accounted for $52.1 \%$. Higher incidence of the isolates was found among subjects with age category $26-30$ years with prevalence of $17.4 \%$. The finding of this study justify the findings of Ronaldo [7] who describe that the commonest etiologic agents of UTI include Escherichia coli, Klebsiella sp, Staphylococcus aureus, Pseudomonas sp and Streptococcus. This finding was contrary to that of Alemu et al. [4] who found that the prevalence of Klebsiella sp among UTI patients is $10 \%$. This organism is mainly from the external genitalia, vagina, the genital tract, rectum, and gastro-intestinal tract. It may involve the lower urinary tract or the bladder [8]. It generally infect cells in the urinary tract 
Prevalence of Klebsiella Pneumoniae Isolated from Pregnant Women with Urinary Tracts Infections

by initial attachment and subsequent ascension from the urethra, to the bladder, kidney and through the systemic circulation, causing bacteraemia, as a result of the renal cells being compromised [29].

\section{ConClusion}

Urinary tract infections (UTIs) are one of the most common infectious diseases. The finding of this study revealed that the overall prevalence of urinary tract infection among pregnant women complaining of lower abdominal pains in this study was found to be $15.8 \%$. The infection is caused is mainly caused by both Gram positive and negative bacteria one of which is $K$. pneumoniae. According to the study, K. pneumoniae is Gram negative rod bacterium, non-motile, positive for nitrate reduction, VP and citrate utilization test, negative for indole and MR test and lactose fermenter. From a total of 23 urine samples examined for the presence of $K$. pneumoniae, 12 samples were positive for K. pneumoniae which accounted for $52.1 \%$. Health educational programs on preventive and control of the microbial infection among pregnant women should be provided.

\section{REFERENCES}

[1] Kolawale AS, Kolawale OM, Kandaki-Olukemi YT, Babatunde SK, Durowade KA, and Kplawale CF. Prevalence of urinary tract infections among patients attending Dalhatu Araf Specialist Hospital, Lafia, Nasarawa State, Nigeria. Int. J. Med. Med. Sci. 2009; 1(5):163-167.

[2] Pezzlo M. Detection of urinary tract infections by rapid methods, Clin. Microbiol.Rev. 1988 1(3): 268280 .

[3] Bonadio MM, Meini P, Spitaleri and Gigli C. Current microbiological and clinical aspects of urinary tract infections. European. Urol. 2001; 40(4):439 445 .

[4] Alemu A, Moges F, Shiferaw Y, Tafess K, Kassu A and Anagaw B. Bacterial profile and drug susceptibility pattern of urinary tract infection in pregnant women at University of Gondar Teaching Hospital, Northwest Ethiopia, BMC Research 2012; 5(197)

[5] Assefa A, Asrat D, Woldeamanuel Y, Hiwot YG, Abdella A and Melesse T. Bacterial profile and drug susceptibility pattern of urinary tract infection in pregnant women at Tikur Anbessa Specialized Hospital Addis Ababa, Ethiopia, Ethiopian Medical Journal, 2008; 46 (3) 227-235.

[6] Okonko IO, Ijandipe LA, Ilusanya OA, Donbraye Emmanuel OB, Ejembi J, Udeze AO et al. Detection of Urinary Tract Infection (UTI) among pregnant women in Oluyoro Catholic Hospital, Ibadan, South-Western Nigeria, Malaysian Journal of Microbiology, 2010; 6 (1) 16-24.

[7] Ronaldo A. The etiology of urinary tract infections: traditional and emerging pathogens. Dis Mon. 2003; 49(2):71-82.

[8] EricaFreire de Vasconcelos-Pereira et al. Urinary Tract Infection in High Risk Pregnant Women. Rev Patol Trop. 2013; 42(1):21-9.

[9] Hind, H.A., Asmaa, H.A. and Mohammed, H. 2016. Isolation And Identification of Aerobic Bacteria Detected from Sheep Infected with Pneumonia. Adv. Environ. Biol., 10(5): 214-219.

[10] Vinetz J. Antibiotic guide: Klesiella species. Assessed from http://prod.hopkinsabxguide. org/ pathogens/bacteria/aerobic gram negative bacilli/klebsiella species.html? 2007; contentInstanceId=255888.

[11] Nordamann P, Cuzon G and Naas T. The real threat of Klebsiella pneumonia carbapenemaseproducing bacteria . Lancet Infec Dis. 2009; 9 (4):228- 236.

[12] Graybill JR, Marshall LW, Charache P, Wallace CK and Melwin VK. Nosocomial pneumonia: A continuing major problem. Am. Rev. Respir. Dis. 1973; 108:1130-1140.

[13] Mathur NB, Khalib A, Sarkar R and Puri RK. Mortality in neonatal septicaaemia with involvement of mother in management. Ind. J. Pediatri. 1991; 28 (2) 1259-1264.

[14] Sarathbabu R, Ramani TV, Bhaskara rao K and Supriya Panda. Antibiotic susceptibility pattern of Klebsiella pneumoniae isolated from sputum, urine and pus samples. IOSR J. Pharma. Bio.l Sci. 2012; 1(2) pp 04-09.

[15] Savita jadhav, Rabindranath misra, Nageshawari gandham, Mahadev ujagare, et al. Increasing Incidence of Multidrug Resistance Klebsiella 
Prevalence of Klebsiella Pneumoniae Isolated from Pregnant Women with Urinary Tracts Infections

Pneumoniae Infections In Hospital And Community Settings. Inter. J. Microbiol. Res.2012; 4 (6): 253-257.

[16] Wondimeneh Y, Muluye D, Alemu A, Atinafu A, Yitayew G, Gebrecherkos T, Damtie D, Ferede G. urinary tract infection among obstetric fistula patients at Gondar University Hospital, Northwest Ethiopia. BMC Womens Health 2014; 17: 14-22.

[17] Susethira A R and Uma A Prevalence of Klebsiella Bacteriuria and Antimicrobial Susceptibility in a Tertiary Care Hospital, Tiruchirapalli, India. International Journal of Pharmaceutical and Clinical Research 2016; 8(6): 538-542

[18] National Population Commission (NPC). National population census result, 2006 Abuja Nigeria

[19] Nwabuisi EC and Onile BA “Male Infertility among Sexually Transmitted Disease Clinic Attendees in Ilorin," Nigerian Journal of Medicine, 2001; 10 (2): pp. 68-71.

[20] Chessbrough M. District laboratory practice in tropical countries, second edition, part two, Cambridge university press. Examination of pus, ulcer material and skin specimens.2006; pp 80-85

[21] Holt JG, Krieg NR, Senath PHA., Staley JT and Williams ST. Bergey's Manual of Determinative Bacteriology 9th Ed. Baltimore Md Williams and Wilkins 1994

[22] Bauer AW, Kirby WM, Sherris JC and Turck M. Antibiotic susceptibility testing by a standardized single disk method. Am J Clin Pathol. 1996; 45: 493-496.
[23] CLSI, (2010) "Performance standards for antimicrobial susceptibility testing," Twentieth informational supplement, Clinical and Laboratory Standards Institute Doc. M100eS20, 2010.

[24] Rowinska JM, Malyszko J and Wieliczko M. Urinary tract infections in pregnancy old and new unresolved diagnostic and therapeutic problems. Arch Med Sci. 2015; 11(1): 67-77.

[25] Mikhail M and Anyaegbunam A "Lower urinary tract dysfunction in pregnancy: A review," Obstet Gynecol Surv., 1995; vol. 50, pp. 675-83.

[26] Mohamed A and Fareid Frequency and susceptibility profiles of bacteria causing urinary tract infection among women, New York Science Journal, 2012; 5(2): 284-298

[27] Nabbugodi WF, Gichuhi JW and Mugo NW. Prevalence of Urinary Tract Infection, Microbial Aetiology, and Antibiotic Sensitivity Pattern among Antenatal Women Presenting with Lower Abdominal Pains at Kenyatta National Hospital, Nairobi, Kenya. The Open Access Journal of Science and Technology 2015; 3 pp 1-6 doi:10.11131/2015/101115

[28] Nwachukwu E, Onyebuchi O, Michael 0. Prevalence of urinary tract infections in pregnant women in Onitsha, Nigeria. J Bacteriol Mycol. 2018; 6(5):284-285. DOI: 10.15406/ jbmoa.2018.06.00219

[29] Kaper JB, Nataro JP and Mobley HLT Pathogenic Escherichia coli Nature Reviews Microbiology. 2004; 2, 123-140.

Citation: Farouk S. Nas, Ibrahim U. Imam, Muhammad Ali, et al. Prevalence of Klebsiella Pneumoniae Isolated from Pregnant Women with Urinary Tracts Infections. Archives of Urology. 2019; 2(1): 32-38.

Copyright: (c) 2019 Farouk S. Nas, Ibrahim U. Imam, Muhammad Ali, et al. This is an open access article distributed under the Creative Commons Attribution License, which permits unrestricted use, distribution, and reproduction in any medium, provided the original work is properly cited. 